\title{
Resilience, Social Support, and Meaning in Life among Koreans During Midlife
}

\author{
Jeong-Sook Lee \\ Assistant Professor, Department of Nursing, Sangmyung University, Republic of Korea
}

\begin{abstract}
Background: Toinvestigatethe associationsbetweenresilience, social support, and meaning in lifeduring midlife and the factors related to meaning in life.

Methods:In this cross-sectionalstudy conducted from May 22 to June 21, 2019, 159 South Koreans aged 40-64years were surveyed about resilience, social support, meaning in life, and personal characteristics. Descriptive statistics, t-tests, analysis of variance, bivariate Pearson's correlations, and multiple regression analyses were performed.

Conclusion: The difference in resilience according to general characteristics showed significant differences in age, educational attainment, religious affiliation, and health status.Differencesin social support were significantly correlated to gender, social class, and health status. Meaning in life varied significantly according to differences in religious affiliation, social class, and health status. Resilience, social support, and meaning in life were significantly correlated. In the multiple regression model, resilience, social support, and selfrated health statussignificantly influencedmeaning in life. Strengthening resilience andsocial supportduring midlife mightincrease meaning in life, in turn,positively influencing thequality of life inold age.
\end{abstract}

Keywords:meaning in life, middle adulthood, midlife, resilience, social support

\section{Introduction}

Middle adulthood (midlife), a developmental stage between young adulthood and old age, has been increasingly receiving scholarly attention because of increased life expectancy owing to the medical advances ${ }^{1}$.This period of the life course is work- and family-oriented ${ }^{2}$. Middle-aged individuals in South Korea are responsible for both their dependent children and parents, and therefore, must be financially stable and

\section{Correspondence Author}

Jeong-Sook Lee,

31, Sangmyungdaero, Dongnamgu, Cheonan City, Chungnam 31066, Republic of Korea.

Phone: $+8210-5491-3912$

Fax: +82504-267-3912

Email: luckyjs34@hanmail.net have adequate healthcare to ensure thefulfillment of their familial obligations ${ }^{1}$. Lifespan extension is characteristic of aging societies, and health during midlife should be in focus to help ensure health and wellbeing during old age $^{3}$. More importantly, midlife is a period when one's life thus far is given meaning ${ }^{4}$.

In some rapidly changing societies, people tend to experience decreased value of life and feel inner emptiness, and some studies have found that considering one's life to be meaningful is particularly important for health during midlife ${ }^{5,6}$. Meaning in life is related to a personal assessment of the purpose of life and has been found to significantly influence mental health and wellbeing ${ }^{7}$ because it orients people toward actively living and urges them to accomplish worthwhile things ${ }^{8}$.

Meaning in life develops from personal experiences that support (or do not support) a sense of purpose ${ }^{2}$. The 
sense that one's life has meaning helps people interpret their experiences positively, which is then reinforced by positive emotions ${ }^{9}$. Pursuing meaning in life might increase a person's sense of self-worth, thereby buffering the effects of adversity by supporting positive responses and stability ${ }^{8}$. In addition, meaning in life might increase life satisfaction, as people with relatively more meaning in life are more satisfied, positive, and open-minded ${ }^{8}$. Moreover, people who believed their lives were meaningful adapted better with less negativity and reported lower levels of depression and anxiety than those with less meaning in life ${ }^{10}$.

The developmental tasks of midlife include finding a sense of meaning in life and reconstructing personal identity ${ }^{11}$. Since meaning in life is vital to the psychological and spiritual aspects of developmental tasks, people should prioritize its pursuit in midlife ${ }^{12}$. Moreover, given that establishing meaning in life during midlife is critical for achieving successful and happy aging, this should be a period of growth with balance; thus, studying midlife from an integrative perspective is necessary ${ }^{1}$.

Resilience is defined as the ability to successfully deal with and withstand stress or adversity ${ }^{13,14}$. It improves individuals' adaptive capacities by transforming negative emotions into positive emotions ${ }^{15}$. Resilience is an innate trait involving optimism, which creates happiness ${ }^{15}$, and everyone has some level of resilience with which they cope and grow through stressful and adverse experiences ${ }^{16}$. Previous research has found that resilience is positively correlated with optimism ${ }^{17}$, and meaning in life ${ }^{18}$.

Social support is one of the most effective ways to cope with stressful situations ${ }^{19}$. Regardless of maladjustment problems, social support might prevent and resolve psychological or social challenges ${ }^{19}, 20$.As midlife is a significant transitional period, people might feel highly stressed or experience psychological crises ${ }^{1}$. Despite this being a period of increased social activities, middle-aged people perceive that they are less socially supported and are less aware of social support because they think they have few resources to help in a crisis ${ }^{21}$. Social relationships might help people find meaning in life and live healthy lives ${ }^{22}$. Thus, social support is a significant variable that affects one's meaning in life during midlife ${ }^{4}$.

Although previous studies found that resilience and social support were related to optimism and meaning in life, the associations between these variables during midlife are poorly understood. It is necessary to clarify the roles of resilience and social support as correlates of meaning in life during midlife to promote healthy and successful aging. Accordingly, this study investigated the associations between resilience, social support, and meaning in life during midlife in a sample of South Koreans. The findings could be used as a reference for developing national-level studies aimed at improving quality of life throughout the life course.

\section{Materials and Method}

Design: This study employed a cross-sectional design.

Participants and data collection: Convenience sampling was employed to recruit people known to the researchers through avenues such as social gatherings and town meetings. The study procedurewas explained to potential participants. They were assured of the confidentiality of their data and that they could withdraw at will at any time. Individuals who indicated that they understood this information and provided written informed consent were included in the study. The Institutional Review Board of S University (SMUIRB; AP-2019-001) approved the study. The inclusion criteria for participants were that they had to be age 40-64 years and Korean. Finally, 159 participants were included. The desired sample size was determined using G*Power 3.1.9.2 with the following input parameters: effect size $=.15$, significance level of $p=.05$, power $=.90$, and number of predictors $=11$. The minimum sample size was identified as 152.A researcher either mailed the questionnaires to a representative or handed them over during a meeting; subsequently, the representative distributed them and collected the completed versions. 
The collected questionnaires were either returned in person or via mail. The data were collected between May 22 and June 21, 2019.

Measurement: Meaning in life was measured using the Korean version of the Meaning in Life Questionnaire $^{23}$; the translation and validation were undertaken by Won et al. ${ }^{7}$. The 10 items were scored on a seven-point Likert scale where $1=$ absolutely untrue and $7=$ absolutely true. Higher scores indicated more meaning in life, and the tool's internal reliability as demonstrated by Cronbach's alpha was .93 .

Resilience was measured using the ConnorDavidson Resilience Scale ${ }^{13}$. The 25 items were scored on a five-point Likert scale where $1=$ not at all true and $5=$ true most of the time. Higher scores indicated more resilience. The Cronbach's alpha was .90.

Social support was measured using the Perceived Social Support Scale ${ }^{24}$. The 12 items were rated on a seven-point Likert scale where $1=$ very strongly disagree and $7=$ very strongly agree. Higher scores indicated more perceived social support, and Cronbach's alpha was .93.

\section{Statistical Analysis}

All analyses were performed using SPSS/WIN 21.0 (IBM Corp., Armonk, NY, USA). Descriptive statistics (frequencies, percentages, means, and standard deviations) were generated. Then, independent samples t-tests and one-way analysis of variance tests were used to assess the differences in resilience, social support, and meaning in life by the participants' characteristics, and Scheffe's tests were performed for the post hoc analysis. Pearson's correlation coefficients were computed to assess the bivariate correlations among the key variables, and a multiple correlation regression analysis was performed to estimate the effects of resilience and social support on meaning in life.

\section{Results and Discussion}

General characteristics of the subjects: As shown in Table 1,there were slightly more females (54.1\%) than males, and most respondents were aged 40-59. Approximately $7 \%$ werenot married, $59.1 \%$ had an educational level of college or higher, $59.7 \%$ did not have any religious affiliation, $90.6 \%$ wereemployed, and $83 \%$ considered themselves middle class.Finally,less than $6 \%$ had poor health status.

Table 1. General characteristics of the subjects $(\mathrm{N}=159)$

\begin{tabular}{|c|c|c|}
\hline Variable & Category & N(\%) or M \pm SD \\
\hline \multirow{2}{*}{ Gender } & Male & $73(45.9)$ \\
& Female & $86(54.1)$ \\
\hline & & $72(45.3)$ \\
Age & $40-49$ & $72(45.3)$ \\
& $50-59$ & $15(9.4)$ \\
\hline Marital status & $60-64$ & $50.58 \pm 5.75$ \\
& Mean & $11(6.9)$ \\
\hline & Unmarried & $148(93.1)$ \\
\hline
\end{tabular}


Cont... Table 1. General characteristics of the subjects $(\mathrm{N}=159)$

\begin{tabular}{|c|c|c|}
\hline Religious affiliation & No & $95(59.7)$ \\
& Yes & $64(40.3)$ \\
\hline \multirow{2}{*}{ Employment } & Yes & $144(90.6)$ \\
& No & $15(9.4)$ \\
\hline \multirow{3}{*}{ Economic status } & Upper & $11(6.9)$ \\
& Middle & $132(83.0)$ \\
& Lower & $16(10.1)$ \\
\hline \multirow{2}{*}{ Health status } & Good & $55(34.6)$ \\
& Moderate & $95(59.7)$ \\
& Poor & $9(5.7)$ \\
\hline
\end{tabular}

Degree of resilience, social support, and meaning in life: As shown in Table 2, the mean resilience score was $3.69 \pm 0.45$ on a five-point scale, and those for social support and meaning in life were $5.72 \pm 0.85$ and $5.43 \pm 0.99$, respectively, on a seven-point scale.

Table 2. Degree of resilience, social support, and meaning in life $(\mathrm{N}=159)$

\begin{tabular}{|c|c|c|}
\hline Variable & M \pm SD & Range \\
\hline & & \\
Resilience & $3.69 \pm 0.45$ & $2.60-4.92$ \\
Social support & $5.72 \pm 0.85$ & $2.17-7.00$ \\
Meaning in life & $5.43 \pm 0.99$ & $2.00-7.00$ \\
\hline
\end{tabular}

Differences in resilience, social support, meaning in life depending on general characteristics: As shown in Table 3, significant differences in resilience were found for age $(\mathrm{F}=3.70, \mathrm{p}=.027)$, education attainment $(\mathrm{F}=3.41, \mathrm{p}=.036)$, religious affiliation $(\mathrm{t}=-2.10, \mathrm{p}=.037)$, and health status $(\mathrm{F}=12.06, \mathrm{p}<.001)$. Participants aged 50-59 had higher mean resilience than those aged 40 49 , and those with a graduate education or higher had higher resilience scores than those with high school or less education. Those with a religious affiliation had higher mean resilience than those without. Lastly, the better the health of the group, the higher the resilience. These results support a previous study that found higher resilience among Christians than among non-religious people ${ }^{25}$, and health seemed positively correlated with resilience ${ }^{26}$. Regarding resilience in middle-aged adults, studies making gender-stratified comparisons are scarce and not comparable to the present study, and the lack of a gender difference in the present study should be investigated further using a larger sample of middleaged South Koreans.

Significant differences in social support were found for gender $(\mathrm{t}=-3.41, \mathrm{p}=.001)$, economic status $(\mathrm{F}=10.76$, $\mathrm{p}<.001)$, and health status $(\mathrm{F}=5.31, \mathrm{p}=.006)$. The mean social support score for women was significantly higher than for men. This may be because women's social and economic activities increase in middle age ${ }^{27}$, and as interpersonal relations expand, they perceive higher social support.Furthermore, social support was higher in the upper or middle economic group, and they had better health. These results are consistent with the results of a previous study ${ }^{21}$, wherein social support was higher when one was in a higher economic group and 
had a better state of health. During midlife, one's close relationship with family, work and society, and social roles are important. Such social and environmental conditions are likely to result in conflicts ${ }^{21}$, emphasizing the need to secure resources to help overcome crises.

Significant differences in meaning in life were found for religious affiliation $(\mathrm{t}=-2.21, \mathrm{p}=.028)$, economic status $(\mathrm{F}=7.11, \mathrm{p}=.001)$, and health status $(\mathrm{F}=15.92$, $\mathrm{p}<.001)$. Those with a religious affiliation had higher mean meaning in life than those without. The meaning in life was higher in the upper or middle economic groups, and they had better health. This supports previous research that found that religion promoted meaning in life and helped individuals lead healthier $\operatorname{lives}^{28}$, and studies that found that economic status and health were positively correlated with meaning in $\operatorname{life}^{4}$. As familial and financial responsibilities tend to be stressful during midlife, meaning in life might decrease during this period. In the present study, those who belonged to a low economic status had less meaning in life; therefore, it is important to help them successfully handle challenging situations ${ }^{5}$.

Table 3. Differences in resilience, social support, and meaning in life depending on the general characteristics of the subjects $(\mathbf{N}=159)$

\begin{tabular}{|c|c|c|c|c|c|c|c|}
\hline \multirow[b]{2}{*}{ Variable } & \multirow[b]{2}{*}{ Category } & \multicolumn{2}{|c|}{ Resilience } & \multicolumn{2}{|c|}{ Social support } & \multicolumn{2}{|c|}{ Meaning in life } \\
\hline & & $\mathbf{M} \pm \mathbf{S D}$ & $\mathbf{t} / \mathbf{F}(\mathbf{p})$ & $\mathbf{M} \pm \mathbf{S D}$ & $\mathbf{t} / \mathbf{F}(\mathbf{p})$ & $\mathbf{M} \pm \mathbf{S D}$ & $\mathbf{t} / \mathbf{F}(\mathbf{p})$ \\
\hline Gender & $\begin{array}{c}\text { Male } \\
\text { Female }\end{array}$ & $\begin{array}{l}3.70 \pm 0.48 \\
3.68 \pm 0.42\end{array}$ & $\begin{array}{c}0.36 \\
(.721)\end{array}$ & $\begin{array}{l}5.47 \pm 0.95 \\
5.92 \pm 0.70\end{array}$ & $\begin{array}{l}-3.41 \\
(.001)\end{array}$ & $\begin{array}{l}5.41 \pm 1.09 \\
5.46 \pm 0.90\end{array}$ & $\begin{array}{l}-0.28 \\
(.778)\end{array}$ \\
\hline Age & $\begin{array}{l}40-49 a \\
50-59 b \\
60-64 c\end{array}$ & $\begin{array}{l}3.58 \pm 0.39 \\
3.78 \pm 0.47 \\
3.74 \pm 0.37\end{array}$ & $\begin{array}{l}3.70 \\
(.027) \\
(a<b)\end{array}$ & $\begin{array}{l}5.70 \pm 0.81 \\
5.74 \pm 0.90 \\
5.68 \pm 0.86\end{array}$ & $\begin{array}{c}0.05 \\
(.954)\end{array}$ & $\begin{array}{l}5.29 \pm 1.00 \\
5.56 \pm 1.02 \\
5.54 \pm 0.69\end{array}$ & $\begin{array}{c}1.45 \\
(.238)\end{array}$ \\
\hline Marital status & $\begin{array}{c}\text { Unmarried } \\
\text { Married }\end{array}$ & $\begin{array}{l}3.69 \pm 0.57 \\
3.69 \pm 0.44\end{array}$ & $\begin{array}{l}-0.01 \\
(.998)\end{array}$ & $\begin{array}{l}5.76 \pm 0.94 \\
5.71 \pm 0.85\end{array}$ & $\begin{array}{c}0.16 \\
(.876)\end{array}$ & $\begin{array}{l}5.12 \pm 0.98 \\
5.46 \pm 0.99\end{array}$ & $\begin{array}{l}-1.11 \\
(.270)\end{array}$ \\
\hline $\begin{array}{l}\text { Educational } \\
\text { attainment }\end{array}$ & $\begin{array}{c}\leq \text { High schoola } \\
\text { Collegeb } \\
\geq \text { Graduate } \\
\text { school c }\end{array}$ & $\begin{array}{l}3.62 \pm 0.46 \\
3.69 \pm 0.44 \\
3.93 \pm 0.35\end{array}$ & $\begin{array}{l}3.41 \\
(.036) \\
(a<c)\end{array}$ & $\begin{array}{l}5.61 \pm 0.89 \\
5.73 \pm 0.85 \\
6.08 \pm 0.64\end{array}$ & $\begin{array}{c}2.26 \\
(.108)\end{array}$ & $\begin{array}{l}5.25 \pm 1.09 \\
5.51 \pm 0.93 \\
5.79 \pm 0.69\end{array}$ & $\begin{array}{c}2.62 \\
(.076)\end{array}$ \\
\hline $\begin{array}{l}\text { Religious } \\
\text { affiliation }\end{array}$ & $\begin{array}{l}\text { No } \\
\text { Yes }\end{array}$ & $\begin{array}{l}3.63 \pm 0.43 \\
3.78 \pm 0.46\end{array}$ & $\begin{array}{l}-2.10 \\
(.037)\end{array}$ & $\begin{array}{l}5.63 \pm 0.93 \\
5.85 \pm 0.71\end{array}$ & $\begin{array}{l}-1.73 \\
(.086)\end{array}$ & $\begin{array}{l}5.30 \pm 0.97 \\
5.65 \pm 0.99\end{array}$ & $\begin{array}{l}-2.21 \\
(.028)\end{array}$ \\
\hline Employment & $\begin{array}{l}\text { Yes } \\
\text { No }\end{array}$ & $\begin{array}{l}3.71 \pm 0.45 \\
3.51 \pm 0.33\end{array}$ & $\begin{array}{l}1.65 \\
(.100)\end{array}$ & $\begin{array}{l}5.71 \pm 0.87 \\
5.83 \pm 0.74\end{array}$ & $\begin{array}{l}-0.52 \\
(.604)\end{array}$ & $\begin{array}{l}5.46 \pm 1.00 \\
5.21 \pm 0.91\end{array}$ & $\begin{array}{c}0.92 \\
(.360)\end{array}$ \\
\hline Economic status & $\begin{array}{l}\text { Upper a } \\
\text { Middle b } \\
\text { Lower c }\end{array}$ & $\begin{array}{l}3.73 \pm 0.46 \\
3.71 \pm 0.44 \\
3.44 \pm 0.49\end{array}$ & $\begin{array}{c}2.73 \\
(.068)\end{array}$ & $\begin{array}{l}5.83 \pm 0.85 \\
5.82 \pm 0.80 \\
4.83 \pm 0.82\end{array}$ & $\begin{array}{c}10.76 \\
(<.001) \\
(a, b>c)\end{array}$ & $\begin{array}{l}5.62 \pm 1.06 \\
5.52 \pm 0.90 \\
4.59 \pm 1.26\end{array}$ & $\begin{array}{c}7.11 \\
(.001) \\
(\mathrm{a}, \mathrm{b}>\mathrm{c})\end{array}$ \\
\hline Health status & $\begin{array}{c}\text { Good a } \\
\text { Moderate b } \\
\text { Poor c }\end{array}$ & $\begin{array}{l}3.86 \pm 0.48 \\
3.63 \pm 0.37 \\
3.18 \pm 0.47\end{array}$ & $\begin{array}{c}12.06 \\
(<.001) \\
(a>b>c)\end{array}$ & $\begin{array}{l}5.99 \pm 0.72 \\
5.61 \pm 0.86 \\
5.21 \pm 1.16\end{array}$ & $\begin{array}{c}5.31 \\
(.006) \\
(a>b>c)\end{array}$ & $\begin{array}{l}5.87 \pm 0.79 \\
5.30 \pm 0.94 \\
4.19 \pm 1.23\end{array}$ & $\begin{array}{l}15.92 \\
(<.001) \\
(a>b>c)\end{array}$ \\
\hline
\end{tabular}


Correlation among resilience, social support, perceived by people with high resilience increased and meaning in life: Table 4 shows that the three as they actively and positively overcame difficult variables were moderately correlated.These results situations ${ }^{26}$. support previous studies reporting that the social support

Table 4. Correlation among resilience, social support, and meaning in life $(N=159)$

\begin{tabular}{|c|c|c|c|}
\hline Variable & $\begin{array}{c}\text { Resilience } \\
\mathbf{r}(\mathbf{p})\end{array}$ & $\begin{array}{c}\text { Social support } \\
\mathbf{r}(\mathbf{p})\end{array}$ & $\begin{array}{c}\text { Meaning in life } \\
\mathbf{r}(\mathbf{p})\end{array}$ \\
\hline Resilience & 1 & & \\
Social support & $.48(<.001)$ & 1 & 1 \\
Meaning in life & $.63(<.001)$ & $.51(<.001)$ & \\
\hline
\end{tabular}

Factors that influenced the participants' meaning in life: As per the preliminary analyses, there were significant differences in meaning in life by religious affiliation, economic status, and health status (Table 3), and these three variables were converted into dummy variables and tested along with resilience and social support in the multiple regression analysis. Table 5 presents the results, which indicated that the model was statistically significant $(\mathrm{p}<.001)$, explaining about $45.4 \%$ of the variance in meaning in life. The Durbin-Watson test was performed to determine the independence of the residuals. The result was 2.17 , indicating no correlations. The tolerance of $0.72-$ 0.97 and variance inflation factor of $1.03-1.38$ indicated no multicollinearity problems.

The variable with the strongest influence on meaning in life was resilience $(\beta=.46, p<.001)$, followed by social support $(\beta=.25, \mathrm{p}<.001)$ and health status $(\beta=.13, \mathrm{p}=.041)$. These results support previous studies reporting that resilience significantly predicted the sense of a meaningful life ${ }^{29}$, and social support and meaning in life were positively correlated ${ }^{4,30}$.

Table 5. Factors that influenced the participants' meaning in life $(\mathrm{N}=159)$

\begin{tabular}{|c|c|c|c|c|c|}
\hline Variable & $\mathbf{B}$ & $\mathbf{S E}$ & $\boldsymbol{\beta}$ & $\mathbf{t}$ & $\mathbf{p}$ \\
\hline (Constant) & -0.14 & 0.53 & & -0.26 & .798 \\
Religious affiliation & 0.12 & 0.12 & 0.06 & 0.97 & .332 \\
Economic status & 0.03 & 0.23 & 0.01 & 0.12 & .903 \\
Health status & 0.27 & 0.13 & 0.13 & 2.06 & .041 \\
Resilience & 1.02 & 0.15 & 0.46 & 6.71 & $<.001$ \\
Social support & 0.29 & 0.08 & 0.25 & 3.69 & $<.001$ \\
& \multicolumn{2}{l}{} \\
\hline
\end{tabular}




\section{Conclusion}

This study's results provide a basis for the formulation of strategies to strengthen meaning in life during midlife. To strengthen social support and resilience, it is necessary to build resources customized to the surroundings and utilize them in a healthy way. To promote health - a factor influencing the meaning of life - daily exercise and healthy lifestyle practices are necessary.

Despite some significant findings, this study has limitations that cannot be overlooked. Owing to the small sample size and use of convenience sampling, the results are not generalizable to all middle-aged South Koreans. Future studies should examine the relationships between resilience, social support, and meaning in life using population data.

Ethical Clearance:Taken from the Institutional Review Board of S University (SMUIRB; AP-2019001).

Source of Funding: No funding was received for this study.

Conflict of Interest: The author has no relevant financial or non-financial interests to disclose.

\section{References}

1. Park JM. Development and validation of the middle-age meaning in life scale (Unpublished doctoral dissertation). South Korea: Kyungsung University, Pusan; 2018.

2. Ko HJ. Pathways to well-being: A mixed methods study on purpose in life in middle adulthood (Unpublished doctoral dissertation). USA: Oregon State University, Corvallis; 2015.

3. Kang YH. Effects of family support and social support on life satisfaction of middleaged men. The Journal of the Korea Contents Association. 2016;16(2):344-353. doi:10.5392/ JKCA.2016.16.02.344

4. Chang HK, Sohn JN. Factors related to meaning of life in middle adults. Asia-Pacific Journal of Multimedia Services Convergent with Art, Humanities, and Sociology. 2017;7(7):609-621.
5. Choi SO, Kim SN, Shin KI, Lee JJ. Meaning in life of a resident community of normal adults. KJAN. 2002;14(3):359-367.

6. Van Orden KA, Bamonti PM, King DA, Duberstein PR. Does perceived burdensomeness erode meaning in life among older adults? Aging Ment. Health. 2012;16(7):855-860. doi:10.1080/1360786 3.2012 .657156

7. Won D, Kim KH, Kwon SJ. Validation of Korean version of Meaning in Life Questionnaire. The Korean Journal of Health Psychology. 2005;10:211-225.

8. Park SY, Kwon SM. A theoretical review with clinical implications for the meaning in life. Korean Journal of Psychology: General. 2012;31:741-768.

9. King LA, Hicks JA, Krull JL, Del Gaiso AK. Positive affect and the experience of meaning in life. J Pers Soc Psychol. 2006;90(1):179-196. doi:10.1037/0022-3514.90.1.179

10. Yek MH, Olendzki N, Kekecs Z, Patterson V, Elkins G. Presence of meaning in life and search for meaning in life and relationship to health anxiety. Psychol. Rep. 2017;120(3):383-390. doi:10.1177/0033294117697084

11. Kuther TL, Burnell K. A life span developmental perspective on psychosocial development in midlife. Adultspan J. 2019;18(1):27-39. doi:10.1002/adsp.12067

12. Jang $\mathrm{SH}$, Choi SO. A structural modeling of middleagedadults' meaning in life.KJAN.2017;29(4):363372. doi:10.7475/kjan.2017.29.4.363

13. Connor KM, Davidson JRT. Development of a new resilience scale: The Connor-Davidson Resilience Scale (CD-RISC). Depress. Anxiety. 2003;18(2):76-82. doi:10.1002/da.10113

14. Rushton CH, Batcheller J, Schroeder K, Donohue $\mathrm{P}$. Burnout and resilience among nurses practicing in high-intensity settings. Am J Crit Care. 2015;24(5):412-420. doi:10.4037/ajcc2015291

15. Kim JW. Resilience. Goyang: Wisdom house Inc; 2011.

16. Grafton E, Gillespie B, Henderson S. Resilience: The power within. Oncol. Nurs. Forum. 2010;37(6):698-705. doi:10.1188/10.ONF.698705

17. Youn MS, Kim DW. The mediating effects of resilience on the relationship between meaning 
in life and subjective well-being of low-income middle-aged persons. Korean Journal of Educational Therapist. 2017;9:349-366.

18. Işık S, Üzbe N. Personality traits and positive/ negative affects: An analysis of meaning in life among adults. Educational Sciences: Theory and Practice. 2015;15(3):587-595. doi:10.12738/ estp.2015.3.2436

19. Watkins K, Hill EM. The role of stress in the social support-mental health relationship. J. Coll. Couns. 2018;21(2):153-164. doi:10.1002/jocc.12094

20. Lee SH, JeongGY, Jang YW. A study of relations among ego-resilience, social support and satisfaction of department among college students from cosmetology-related departments. The Journal of Business Education. 2016;30:21-47.

21. ChoiMK,LeeYH.Depression, powerlessness, social support, and socioeconomic status in middle aged community residents. JKPMHN. 2010;19(2):196. doi:10.12934/jkpmhn.2010.19.2.196

22. Jeon HO, Kim AR, Chae MO. A meta-analysis of the variables related to psychological crisis in Korean middle-aged adults. Journal of Korean Public Health Nursing. 2018;32(3):451-467. doi:10.5932/JKPHN.2018.32.3.451

23. Steger MF. Development and validation of the meaning in life questionnaire: A measure of eudaimonic well-being (Unpublished doctoral dissertation). USA: University of Minnesota, Minneapolis; 2005.

24. Zimet GD, Dahlem W, Zime SG, Farley GK. The Multidimensional Scale of Perceived Social Support. J Pers Assess. 1988;52(1):30-41. doi:10.1207/s15327752jpa5201_2

25. Min ES. Relationship between stress, depression, and resilience of middle-aged women. Journal of the Korea Entertainment Industry Association. 2017;6:199-207. doi:10.21184/ jkeia.2017.06.11.4.199

26. Kim NH, Park SY. The relationship between resilience, social support and caring burden of middle-aged caregivers caring for chronic disease. Journal of the Korea Academia-Industrial Cooperation Society. 2019;20(2):300-310. doi:10.5762/KAIS.2019.20.2.300

27. Kim JD, Jung, MY, Kim KB, Noh JW. Effect of social and economic levels of adult women on anxiety and depression symptoms. The Journal of the Korea Contents Association. 2016;16(8):2938. doi:10.5392/JKCA.2016.16.08.029

28. Steger MF, Frazier P. Meaning in life: One link in the chain from religiousness to well-being. J. Couns. Psychol. 2005;52(4):574-582. doi:10.1037/00220167.52.4.574

29. Oh YJ, Yoon SN, Oh EJ. The effect of resilience and retirement attitudes perceived by middle-aged married men on a meaningful life. Journal of Korean Home Management Association. 2016;34(4):157174. doi:10.7466/JKHMA.2016.34.4.157

30. Jang SH, Yeu HN. The factors influencing the meaning in life in middle-aged adults. Journal of the Korea Academia-Industrial Cooperation Society. 2018;19(12):432-440. doi:10.5762/ KAIS.2018.19.12.432 